\title{
Validation of Dietary Antioxidant Index (DAI) and investigating the relationship between DAI and the odds of gastric cancer
}

Farhad Vahid ${ }^{1}$, Diana Rahmani ${ }^{1}$ and Seyed Hossein Davoodi ${ }^{2,3^{*}}$ (]

\begin{abstract}
Background: Gastric cancer (GC) incidence and mortality are rapidly growing worldwide. It is estimated that more than 1,000,000 new cases are diagnosed each year, and more than 78,000 people lose their lives due to GC. The association between dietary antioxidants and GC has been shown in some studies. However, because of the discrepancy between the findings and the lack of a valid indicator, it seems necessary to design and validate the Dietary Antioxidant Index (DAl) to examine the diet's total antioxidant content. The present study aimed to survey the validity of DAI and its association with the odds of GC.
\end{abstract}

Methods: In this hospital-based case-control study, 82 patients with GC and 95 healthy controls were examined. We used a 168-item food frequency questioner to assess dietary intakes. The DAI was calculated based on the intake of vitamin A, C, E, and selenium, manganese, and zinc. We standardized each of the six vitamins and minerals by subtracting the global mean and dividing by the global standard deviation to calculate DAI. We then calculated the DAI by summing up the standardized intakes of these vitamins and minerals of the individuals with equal weight.

Results: We observed a significant correlation between DAl and total antioxidant capacity (TAC) after controlling for age, body mass index (BMI), energy intake, smoking and fasting blood sugar, education, total fat intake, helicobacter pylori infection, total cholesterol, and saturated fatty acid (SFA) intakes. Results obtained from modeling DAl as a continuous variable in relation to GC showed a negative association after adjustment for age and in the multivariable analysis $(O R=0.64, C l=0.43-0.95)$.

Conclusion: DAl is a valid indicator of dietary antioxidants assessments, and it can be used as a predictor of antioxidant status due to its correlation with serum antioxidant levels. The results showed that dietary antioxidants have a significant relationship with GC, which indicates the importance of antioxidants in this cancer's etiology.

Keywords: Gastric cancer, Dietary Antioxidant Index (DAI), Total antioxidant capacity (TAC), Malondialdehyde (MDA), Food Frequency Questionnaire (FFQ)

\section{Introduction}

Gastric Cancer (GC) is one of the most common and pernicious malignancies globally [1]. It is estimated that each year more than 1,033,701 new cases of GC

*Correspondence: hdavoodi1345@gmail.com

${ }^{3}$ Cancer Research Center, Shahid Beheshti University of Medical Sciences, Tehran, Iran

Full list of author information is available at the end of the article are diagnosed, and more than 782,685 people lose their lives due to GC [2]. GC's lifetime risk to age 74 remains between 5 and $20 \%$ in some parts of Asia [2,3]. Given that the therapies for GC are limited, and the survival chance is low, prevention can be a very effective strategy to reduce the mortality from GC [4-6]. Several studies have found a link between the incidence of GC and unhealthy diets $[7,8]$. In addition, the association between dietary antioxidants and the reduction of the original author(s) and the source, provide a link to the Creative Commons licence, and indicate if changes were made. The images or other third party material in this article are included in the article's Creative Commons licence, unless indicated otherwise in a credit line to the material. If material is not included in the article's Creative Commons licence and your intended use is not permitted by statutory regulation or exceeds the permitted use, you will need to obtain permission directly from the copyright holder. To view a copy of this licence, visit http://creativecommons.org/licenses/by/4.0/. The Creative Commons Public Domain Dedication waiver (http://creativeco mmons.org/publicdomain/zero/1.0/) applies to the data made available in this article, unless otherwise stated in a credit line to the data. 
incidence and prevalence of GC has been observed [911]. Therefore, the diet's total antioxidant content can provide a comprehensive overview of the relationship between dietary antioxidants and the incidence and/or risk of GC [12]. Several studies have shown that some foods and micronutrients have antioxidant or/and anti-inflammatory properties [7, 13-16]. Specifically, due to the increase in the incidence and prevalence of various types of cancers, some foods and micronutrient antioxidants are considered more. [18, 20]. Several studies have examined the association between food and micronutrients with antioxidant properties with the incidence and prevalence of various diseases [17-19]. In addition, natural products play a critical role in discovering and developing numerous drugs for the treatment of various types of cancers via different mechanisms [21-23]. These studies have also done well in cancer patients [18, 24-26].

However, most studies have investigated the relationship between foods or micronutrients with antioxidant properties individually or in a limited way, considering the whole diet. Dietary antioxidants can affect interdependent effects and may have a different total effect. Thus, Dietary Antioxidant Index (DAI) was designed to examine the diet's entire antioxidant content. This index has been used in some studies, and significant results have been observed [27-29]. The DAI posits that people's diets can be divided into two major categories: mainly anti-oxidative or mainly oxidative [27]. While further investigation and validation are needed to determine the 'DAI's sensitivity and specificity [27], it can be used to study the nutritional status in a wide range of outcomes. Therefore, this study's main goals are to investigate 'DAI's correlation with the antioxidant level in blood and survey its validity.

Differences in GC subgroups and their relationship with the DAI can respond to how the antioxidant system might influence the mechanisms of prevention or treatment of this cancer $[9,30,31]$. While the possible mechanisms of how dietary antioxidants can prevent or even, in some cases, eliminate cancer cells are very limited, there are several suggested hypotheses for these mechanisms. Antioxidants may inhibit or limit the formation of potential carcinogens (e.g., $\mathrm{N}$-nitroso compounds) associated with GC [9]. A diet high in lipids causes oxidative and inflammatory stress, mediated by cytokines such as tumor necrosis factor-a (TNF-a) and interleukin (IL) -6 and oxidized lipids. The presence of antioxidantsrich foods during a high-fat diet might provide a depot of extrinsic antioxidants, slake radical species produced at the gastric level, and synergize with esoteric antioxidants and providing more efficient protection against oxidative stress [32].
Therefore, considering the limited resources and studies on validating the DAI, the present study examined this index's validity and its association with GC's odds.

\section{Method and materials Participant}

The full protocol of this study has already been published elsewhere [8]. In summary, this hospital-based casecontrol study was conducted from December 2014 to May 2016. Eighty-two patients with GC and ninety-five healthy controls were examined. The cases were patients with GC who were diagnosed by a gastroenterologist within the previous month. Controls were randomly selected from among other 'patients' caregivers attending the same clinics. Controls were frequency-matched on sex and age ( \pm 5 years). Data on cases and controls were collected simultaneously, and both groups were interviewed in the same setting. Informed consent was received from all participants. The local Ethics Review Committee approved the study protocol at Shahid Beheshti University of Medical Sciences, Tehran, Iran.

\section{Inclusion and exclusion criteria Inclusion criteria}

(a) in the control group: the absence of malignancy, pregnancy, lactation or a history of cancer, neurological, gastrointestinal, hepatic, endocrine, immune, kidney and heart disorders and diseases, (b) in case and control groups: the absence of special diets such as vegetarian, or the diets resulting in weight reduction or increase during the year before the interview, (c) in case group: the absence of conditions such as pregnancy, lactation, neurological, gastrointestinal, hepatic, endocrine, immune, kidney and heart disorders and diseases, (d) in both group: being in the age range of 20-80 years and (e) willingness to cooperate in the study.

\section{Exclusion criteria}

(a) To the lack of adherence to the study protocol, (b) major diet changes during the study, including diets aimed at weight increase or decrease, (c) reported intake energy over 5500 or less than $800 \mathrm{kcal} /$ day.

\section{Assessment of antioxidants markers and blood samples Participant preparation}

The case and controls should not have been on any corticosteroids, anti-inflammatory medications, or painkillers for at least $48 \mathrm{~h}$ before collecting specimens.

\section{Biofluid analysis}

After fasting for $10-12 \mathrm{~h}$, venous blood samples $(10 \mathrm{ml})$ were taken in vacutainer tubes under sterile conditions from participants between 08:30-10:30 am. Serum was 
obtained from freshly drawn, rapidly centrifuged. The serum was quickly frozen at $-70{ }^{\circ} \mathrm{C}$ and stored until processed [8].

The serum levels of antioxidants markers, including total antioxidant capacity (TAC) and Malondialdehyde (MDA) for all participants, were measured using Ferric-reducing antioxidant power (FRAP) and Thiobarbituric acid assay (TBA) methods. All participants' antioxidant levels were measured using kits/martials materials produced by Pishtaz Teb Zaman Diagnostics Co., Ltd, and Shanghai Crystal Day Biotech Co., Ltd provided by Negin Salamat Saba Co. Also, serum levels of the low-density lipoprotein (LDL), high-density lipoprotein (HDL), and triglyceride were extracted from patients' medical records.

\section{Assessment of dietary intake}

We used a 168-item food frequency questionnaire (FFQ) to assess the case's dietary intakes and controls over the past year. Case and controls were asked to report each food item's frequency of consumption in the last year according to the standard size units (standard serving size) in the questionnaire.

The information obtained from the questionnaires was then analyzed using Nutritionist IV (First Databank, Hearst Corp., SanBruno, CA, USA) to calculate the average daily intake of energy and nutrients. To calculate the DAI, we use the daily intake of food items affecting the index of antioxidants.

\section{Calculation of DAI and DAQS Scores}

We used two previously validated methods to derive dietary antioxidant indices. The first method, the Dietary Antioxidant Quality Score (DAQS), was adapted from Rivas et al. [33]. The DAQS is calculated based on the intake of six antioxidant vitamins and minerals (vitamin $A$, vitamin $C$, vitamin $E$, selenium, manganese, and zinc) derived from the FFQ. The obtained DAQS was used to calculate antioxidant-nutrient intake. The score refers to the intake of specific vitamins and minerals that have been proven to act as dietary antioxidants: selenium, zinc, vitamin $\mathrm{A}$, vitamin $\mathrm{C}$, and vitamin E. Daily nutrient intake was compared to that of the Recommended Daily Intake (RDI). The intake of each of the five evaluated antioxidant nutrients was assessed separately by assigning a value of zero or one to each nutrient. When the intake was below $2 / 3$ of the RDI, it was assigned a value of zero. Similarly, when the intake was higher than $2 / 3$ of the RDI, it was assigned a value of 1 . Thus, the DAQS ranged from 0 (pro-oxidative diet) to 5 (anti-oxidative diet).

The second method, the DAI, was developed by Wright et al. [27]. We standardized each of the same six dietary vitamins and minerals by subtracting the global mean and dividing the result by the global standard deviation to estimate DAI. We then calculated the DAI by summing up the standardized intakes of these vitamins and minerals and equal weight, as described next $[27,28,33]$ :

$$
\mathrm{DAI}=\sum_{\mathrm{i}=1}^{\mathrm{n}=6} \frac{\text { Individual Intake }- \text { Mean }}{\mathrm{SD}}
$$

\section{Assessment of other variables}

For all participants, the required information about age, sex, place of birth (rural/urban), smoking, alcohol consumption, aspirin/nonsteroidal anti-inflammatory drug (NSAID) use, regular physical activity, education, and family history of cancer was collected through a general information questionnaire during the interviews.

The weights of participants were measured with the least clothes using a SECA digital scale. The height was measured without shoes in standing position, leaning against the wall and shoulder blades under normal circumstances using SECA 206 body meter (Wall mounted height measuring tape). Body Mass Index (BMI) was calculated by dividing weight (in kilograms) by the square of height (square meters).

\section{Statistical analyses}

Descriptive analyses were carried out using paired t-test for the continuous variables and Chi-square test for the categorical variables. DAQS (as dichotomous) was examined across the following characteristics: age, sex, BMI, education, smoking, alcohol, H. pylori infection, physical activity, aspirin/NSAID use, and family history of cancer. Analyses focusing on the association of DAI scores and antioxidant markers were carried out using DAI as a continuous variable. For analyses focusing on $\mathrm{GC}$ as an outcome, the DAI was analyzed both as a continuous variable and as a dichotomous variable, categorized based on the median value of the DAI for the controls $(-0.19)$. Beta estimates and 95\% confidence intervals (CI) for the antioxidant markers were estimated using linear regression and odds ratios (OR), and 95\% CI for GC as an outcome was value assessed using logistic regression models, adjusting only for age and then fitting a model with additional adjustment for alcohol consumption, marital status, physical activity, cancer history in the first-degree family, total antioxidant capacity, vitamin E, manganese, and salt intake. The partial correlation was used to estimate the coefficients between DAI and serum levels of antioxidant factors in the subjects. Statistical tests were performed using SPSS 21; all $p$ values were based on twosided tests. 


\section{Results}

Table 1 shows the distribution of 82 cases of GC and 95 controls according to the selected variable $[7,8]$. The mean age was $48.33 \pm 10.74$ and $51.36 \pm 11.81$ in the case and the control groups, respectively. Controls were significantly had higher BMI and DAI scores compared to controls. The mean DAI value for controls was 0.17 $(\mathrm{SD}=1.18)$ and for the cases were $-0.21(\mathrm{SD}=0.68)$, indicating a more antioxidant diet for controls ( $p$ value $=<0.001)$. The distribution of characteristics and

Table 1 Distribution of 82 gastric cancer cases and 95 controls according to selected variables ${ }^{a, b}[8,38]$

\begin{tabular}{|c|c|c|c|}
\hline \multirow[t]{2}{*}{ Characteristics } & \multicolumn{2}{|c|}{ Mean \pm SD or $\mathrm{N}(\%)$} & \multirow[t]{2}{*}{ p value } \\
\hline & Controls $(n=95)$ & Cases $(n=82)$ & \\
\hline Age (years) & $48.33 \pm 10.74$ & $51.36 \pm 11.81$ & 0.07 \\
\hline $\begin{array}{l}\text { Body Mass Index (BMI, } \\
\mathrm{kg} / \mathrm{m}^{2} \text { ) }\end{array}$ & $24.96 \pm 2.71$ & $26.36 \pm 5.12$ & 0.02 \\
\hline $\begin{array}{l}\text { Dietary antioxidant Index } \\
\text { (DAl) }\end{array}$ & $0.17 \pm 1.18$ & $-0.21 \pm 0.68$ & $<0.01$ \\
\hline TAC (mmol/l) & $1.91 \pm 1.27$ & $1.16 \pm 1.26$ & $<0.01$ \\
\hline MDA $(\mu \mathrm{mol} / \mathrm{l})$ & $3.01 \pm 1.68$ & $3.72 \pm 2.19$ & $<0.01$ \\
\hline Sex & & & 0.98 \\
\hline Females & $52(54.74)$ & $45(54.88)$ & \\
\hline Males & $43(45.26)$ & $37(45.12)$ & \\
\hline Education & & & 0.24 \\
\hline Diploma or less & $67(70.53)$ & $51(62.20)$ & \\
\hline Higher than diploma & $28(29.47)$ & $31(37.80)$ & \\
\hline Smoking & & & 0.82 \\
\hline Never smoker & $80(84.21)$ & $68(82.93)$ & \\
\hline Ever smoker & $15(15.79)$ & $14(17.07)$ & \\
\hline Alcohol & & & 0.41 \\
\hline Non drinker & $86(90.53)$ & $71(86.59)$ & \\
\hline Drinker & $9(9.47)$ & $11(13.41)$ & \\
\hline H. pylori infection & & & $<0.01$ \\
\hline Negative & $46(48.42)$ & $21(25.61)$ & \\
\hline Positive & $49(51.57)$ & $61(74.39)$ & \\
\hline Regular physical activity & & & 0.03 \\
\hline Yes & $30(31.58)$ & $14(17.07)$ & \\
\hline No & $65(68.42)$ & $68(82.93)$ & \\
\hline Aspirin/NSAID use & & & 0.83 \\
\hline No & $86(90.53)$ & $75(91.46)$ & \\
\hline Yes & $9(9.47)$ & $7(8.54)$ & \\
\hline Cancer history & & & 0.41 \\
\hline Yes & $11(11.58)$ & $13(15.85)$ & \\
\hline No & 84 (88.42) & $69(84.15)$ & \\
\hline
\end{tabular}

TAC total antioxidant capacity, $\mathrm{mmol} / /$ millimoles per liter, $M D A$ malondialdehyde, $\mu \mathrm{mol} / \mathrm{I}$ micromoles per liter

a Comparison of mean of case and control groups in case of a normal distribution of variables by the t-test and abnormal distribution of variables by the Mann-Whitney test

b Chi-square was used for categorical variables dietary intakes across DAQS categories were shown in Table 2. Control characteristics by DAI categories are provided in Table 3.

Partial correlation was observed between DAI and serum levels of antioxidant factors in the subjects (Table 4). In model 1, controlling for age, BMI, energy intake, and smoking, acceptable and significant correlation were seen between the DAI and TAC. However, the results did not show a significant correlation between MDA and serum levels of antioxidant factors. In model 2 , after multivariable adjustments, the TAC results were improved, and the correlation observed was stronger and more significant. However, there was still no significant correlation for MDA.

Beta estimates and 95\% confidence intervals for DAI and antioxidant markers are shown in Table 5. significant and acceptable correlation between DAI and TAC were observed after controlling for age, BMI, energy intake, and smoking (model 1), and Additionally controlling for fasting blood sugar, education, total fat intake, $\mathrm{H}$. pylori infection, total cholesterol, and saturated fatty acid intakes (model 2). Nevertheless, there the correlation between DAI and MDA was non-significant and unacceptable in both models.

ORs and 95\% CIs for the odds of GC according to dichotomized DAI scores are shown in Table 5. The results obtained from modeling DAI as a continuous variable in relation to odds of GC showed a negative association after adjustment for age $(O R=0.65$; 95\% $\mathrm{CI}=0.45-0.93)$ and in the multivariable analysis $(\mathrm{OR}=0.64, \mathrm{CI}=0.43-0.95)$. When the analysis was carried out with DAI expressed as a dichotomous variable and adjusting for age, subjects with DAI score $-0.19 \leq$ were at higher odds of having GC compared to subjects with DAI $-0.19>$. However, the OR was not significant $\left(\mathrm{OR}_{\mathrm{DAI}}>-0.19 / \leq-0.19=0.68 ; 95 \%\right.$ $\mathrm{CI}=0.37-1.24)$. In addition, after multivariable adjustment, a higher non-significant odd of having GC were seen. No significant association was seen after analyzing using DAQS and adjusting for age and multivariable adjustment.

\section{Discussion}

The results showed that there is an acceptable and significant correlation between DAI and TAC. Validation of DAI allows researchers to use this proprietary index to examine a comprehensive aspect of the diet in nutritional assessments and researches. There is limited research on the relationship between the total intake of antioxidants and their serum changes. Most studies on dietary antioxidants and their effect(s) on the serum antioxidant levels have examined one or two antioxidants. The interdependent impact of different antioxidants can 
Table2 Distribution of characteristics and dietary intakes across dietary antioxidant quality score (DAQS) categories ${ }^{\mathrm{a}, \mathrm{b}}$ $(\mathrm{n}=177)$

\begin{tabular}{|c|c|c|c|}
\hline \multirow[t]{2}{*}{ Characteristics } & \multicolumn{2}{|l|}{ Mean \pm SD } & \multirow[t]{2}{*}{$p$ value } \\
\hline & $D A Q S \leq 3(n=88)$ & DAQS $>3(n=89)$ & \\
\hline Age (years) & $49.59 \pm 11.30$ & $50.07 \pm 11.45$ & 0.79 \\
\hline Weight (kg) & $59.93 \pm 7.47$ & $59.10 \pm 7.36$ & 0.48 \\
\hline Height (cm) & $165.86 \pm 8.31$ & $167.74 \pm 7.70$ & 0.15 \\
\hline $\mathrm{BMI}\left(\mathrm{k} / \mathrm{m}^{2}\right)$ & $25.95 \pm 4.21$ & $24.85 \pm 3.62$ & 0.09 \\
\hline TNF-a $(p g / m l)$ & $30.74 \pm 26.09$ & $27.51 \pm 24.88$ & 0.44 \\
\hline $\mathrm{TG}(\mathrm{mg} / \mathrm{dl})$ & $139.40 \pm 57.50$ & $136.24 \pm 58.63$ & 0.73 \\
\hline $\mathrm{HDL}(\mathrm{mg} / \mathrm{dl})$ & $46.66 \pm 10.60$ & $47.91 \pm 12.37$ & 0.49 \\
\hline LDL (mg/dl) & $100.05 \pm 30.18$ & $104.98 \pm 31.35$ & 0.32 \\
\hline Energy intake (kcal/day) & $3006.24 \pm 592.47$ & $2990.36 \pm 570.30$ & 0.86 \\
\hline Protein (gr/day) & $106.21 \pm 37.52$ & $104.24 \pm 44.34$ & 0.76 \\
\hline Carbohydrate (gr/day) & $378.92 \pm 122.43$ & $371.84 \pm 101.38$ & 0.70 \\
\hline Total Fat Intake (gr/day) & $111.97 \pm 39.12$ & $114.25 \pm 36.30$ & 0.71 \\
\hline Saturated fatty acid (gr/day) & $45.56 \pm 33.90$ & $47.56 \pm 31.61$ & 0.71 \\
\hline Monounsaturated fat (gr/day) & $29.31 \pm 10.91$ & $30.95 \pm 9.44$ & 0.33 \\
\hline PUFA (gr/day) & $30.49 \pm 19.01$ & $28.49 \pm 18.64$ & 0.51 \\
\hline MUFA 181 (gr/day) & $23.25 \pm 10.07$ & $24.76 \pm 9.40$ & 0.34 \\
\hline PUFA 182 (gr/day) & $25.00 \pm 18.30$ & $22.85 \pm 18.05$ & 0.47 \\
\hline PUFA 183 (gr/day) & $3.70 \pm 2.25$ & $4.14 \pm 2.00$ & 0.22 \\
\hline Sodium (mg/day) & $4109.37 \pm 1664.42$ & $3723.29 \pm 1381.93$ & 0.11 \\
\hline Potassium (mg/day) & $3910.73 \pm 1306.06$ & $3692.42 \pm 1276.97$ & 0.30 \\
\hline Vitamin A (Microgram/day) & $565.66 \pm 243.72$ & $821.25 \pm 375.33$ & $<0.01$ \\
\hline Beta-carotene(Microgram/day) & $5250.19 \pm 2197.20$ & $5152.00 \pm 2145.91$ & 0.78 \\
\hline Alfa-carotene (Microgram/day) & $818.54 \pm 446.58$ & $784.44 \pm 390.25$ & 0.62 \\
\hline Lutein (Microgram/day) & $2241.78 \pm 1006.68$ & $2566.62 \pm 1459.05$ & 0.08 \\
\hline Beta-cryptox (Microgram/day) & $338.73 \pm 160.31$ & $320.51 \pm 172.22$ & 0.49 \\
\hline Lycopene (Microgram/day) & $5047.17 \pm 2329.06$ & $5333.80 \pm 2126.44$ & 0.43 \\
\hline Vitamin C (mg/day) & $149.66 \pm 62.20$ & $175.31 \pm 70.63$ & $<0.01$ \\
\hline Calcium (mg/day) & $1225.30 \pm 466.16$ & $1162.47 \pm 347.51$ & 0.37 \\
\hline Iron (mg/day) & $18.62 \pm 5.87$ & $19.80 \pm 5.18$ & 0.18 \\
\hline Vitamin D (Microgram/day) & $2.14 \pm 1.59$ & $2.30 \pm 1.66$ & 0.56 \\
\hline Vitamin E (mg/day) & $16.69 \pm 6.61$ & $23.89 \pm 8.41$ & $<0.01$ \\
\hline Alfa-tocopherol (mg/day) & $7.47 \pm 4.70$ & $11.36 \pm 5.01$ & $<0.01$ \\
\hline Thiamin (mg/day) & $2.20 \pm 0.93$ & $2.14 \pm 0.80$ & 0.70 \\
\hline Riboflavin (mg/day) & $2.12 \pm 0.72$ & $2.24 \pm 0.79$ & 0.33 \\
\hline Niacin (mg/day) & $28.40 \pm 9.76$ & $31.65 \pm 11.51$ & 0.05 \\
\hline Vitamin B6 (mg/day) & $2.41 \pm 0.93$ & $2.51 \pm 0.94$ & 0.48 \\
\hline Folate (Microgram/day) & $692.70 \pm 236.78$ & $679.14 \pm 238.61$ & 0.72 \\
\hline Vitamin B12 (Microgram/day) & $5.54 \pm 3.50$ & $5.47 \pm 2.78$ & 0.89 \\
\hline Biotin (Microgram/day) & $38.42 \pm 12.82$ & $37.65 \pm 14.59$ & 0.72 \\
\hline Pantothenic (mg/day) & $7.25 \pm 2.57$ & $8.24 \pm 2.68$ & 0.02 \\
\hline Vitamin K (Microgram/day) & $297.55 \pm 152.78$ & $255.96 \pm 142.10$ & 0.08 \\
\hline
\end{tabular}

$\mathrm{kg}$ kilogram, $\mathrm{cm}$ centimeter, BMI Body Mass Index, $\mathrm{k} / \mathrm{m}^{2}$ kilogram per square meter, $T N F-a$ Tumor necrosis factor alpha, $\mathrm{pg} / \mathrm{m} / \mathrm{pictogram} \mathrm{per} \mathrm{milliliter,} \mathrm{mg} / \mathrm{dl} \mathrm{milligram}$ per deciliter, TG triglyceride, HDL high-density lipoprotein, LDL low-density lipoprotein, gr gram, Mufa Monounsaturated fat, Pufa Polyunsaturated fatty acid, $m g$ milligram, gr gram

a Comparison of mean of case and control groups in case of a normal distribution of variables by the t-test and abnormal distribution of variables by the MannWhitney test

${ }^{\mathrm{b}}$ Chi-square was used for categorical variables 
Table 3 Participant characteristics by level of the dietary antioxidant index (DIA) among controls, Iranian Gastric Cancer case-control study ${ }^{a, b}(\mathbf{n}=95)$

\begin{tabular}{|c|c|c|c|}
\hline \multirow[t]{2}{*}{ Characteristics } & \multicolumn{2}{|l|}{ Mean \pm SD or $\mathrm{N}(\%)$} & \multirow[t]{2}{*}{$p$ value } \\
\hline & $\mathrm{DAI} \leq 0.41(n=48)$ & DAI $>0.41(n=47)$ & \\
\hline Age (years) & $48.31 \pm 11.52$ & $48.36 \pm 10.01$ & 0.98 \\
\hline Sex & & & 0.91 \\
\hline Female & $26(54.16)$ & $26(55.31)$ & \\
\hline Male & $22(45.83)$ & $21(44.69)$ & \\
\hline $\begin{array}{l}\text { Body Mass Index } \\
\left(\mathrm{kg} / \mathrm{m}^{2}\right)\end{array}$ & $25.36 \pm 2.73$ & $24.55 \pm 2.65$ & 0.14 \\
\hline $\begin{array}{l}\text { Family history of } \\
\text { cancer }\end{array}$ & & & 0.72 \\
\hline Yes & $5(10.41)$ & $6(12.76)$ & \\
\hline No & $43(89.58)$ & $41(87.23)$ & \\
\hline Education & & & 0.33 \\
\hline $\begin{array}{l}\text { Less than a high } \\
\text { school and } \\
\text { diploma }\end{array}$ & $36(75)$ & $31(65.95)$ & \\
\hline $\begin{array}{l}\text { Higher than } \\
\text { diploma }\end{array}$ & $12(25)$ & $16(34.04)$ & \\
\hline Smoking & & & 0.81 \\
\hline Yes & $8(16.66)$ & $7(14.89)$ & \\
\hline No & $40(83.33)$ & $40(85.10)$ & \\
\hline Alcohol & & & 0.27 \\
\hline No & $45(93.75)$ & $41(87.23)$ & \\
\hline Yes & $3(6.25)$ & $6(12.76)$ & \\
\hline $\begin{array}{l}\text { Regular Physical } \\
\text { Activity }\end{array}$ & & & 0.60 \\
\hline Yes & $14(29.16)$ & $16(34.04)$ & \\
\hline No & $34(70.83)$ & $31(65.95)$ & \\
\hline H. pylori infection & & & 0.47 \\
\hline Yes & $23(47.91)$ & $26(55.31)$ & \\
\hline No & $25(52.08)$ & $21(44.68)$ & \\
\hline Aspirin/NSAID use & & & 0.70 \\
\hline No & $44(91.66)$ & $42(89.36)$ & \\
\hline Yes & $4(8.33)$ & $5(10.63)$ & \\
\hline
\end{tabular}

a Comparison of mean of case and control groups in case of a normal distribution of variables by the $t$-test and abnormal distribution of variables by the Mann-Whitney test

${ }^{\text {b }}$ Chi-square was used for categorical variables

affect overall antioxidant levels of serum. Therefore, getting total antioxidants intake from the diet in a coherent formula and designing an index to predict serum levels of antioxidants is an effective step in assessing nutritional status. The correlations observed in this study showed that this indicator is used in different studies and different outcomes. The correlation between DAI and the TAC was significant and acceptable, while DAI's correlation with MAD was not significant. One explanation could be that TAC is more susceptible to dietary changes, and it is expected that TAC levels modify according to
Table 4 Partial correlation coefficients between dietary antioxidant index (DIA) and serum levels of antioxidant factors $(n=177)$

\begin{tabular}{lllllc}
\hline Model 1 & $\begin{array}{l}\text { Correlation } \\
\text { coefficient }\end{array}$ & $\boldsymbol{p}$ value $^{\mathbf{a}}$ & Model 2 & $\begin{array}{l}\text { Correlation } \\
\text { coefficient }\end{array}$ & $\boldsymbol{p}$ value $^{\mathbf{b}}$ \\
\hline $\begin{array}{c}\text { TAC } \\
(\mathrm{mmol} / \mathrm{l})\end{array}$ & 0.25 & 0.04 & TAC & 0.41 & $<0.01$ \\
$\begin{array}{c}\mathrm{MDA} \\
(\mu \mathrm{mol} / \mathrm{l})\end{array}$ & 0.10 & 0.41 & MDA & 0.09 & 0.47 \\
\hline
\end{tabular}

TAC total antioxidant capacity, $\mathrm{mmol} / \mathrm{I}$ millimoles per liter, $M D A$

malondialdehyde, $B M I$ Body Mass Index, $\mu \mathrm{mol} / / \mathrm{micromole} \mathrm{per} \mathrm{liter,} \mu \mathrm{mol} / /$ micromoles per liter

a Controlling for age, BMI, energy intake, and smoking

b Additionally controlling for fasting blood sugar, education, total fat intake, $H$. pylori infection, total cholesterol, and saturated fatty acid intakes

dietary antioxidant intake. Previously, Wang et al., in 2012, concluded that TAC is a good predictor of dietary and plasma antioxidant status" [34]. These results were in line with the current findings and the significant partial correlation between the DAI and the TAC after multiple controlling for confounders.

In addition, our study showed that DAI is associated with odds of GC. Given the importance of diet and dietary compounds, especially antioxidants, our results confirmed the previous findings in preventing, treating, and controlling various types of cancers. It should be noted that GC is directly related to dietary antioxidants, and the design and use of this index for this type of cancer can be an effective strategy to assess the nutritional status.

The existing relationship between dietary antioxidants with the odds of GC in this case-control study is helpful. These results are consistent with the previous studies. Serafini et al. found an association between antioxidants' equivalent and a reduction in the risk of the cardiac and non-cardiac type of GC [32]. However, Terry et al. concluded that "Antioxidant intake was not associated with the risk of gastric cardia adenocarcinoma" [35]. The impact of dietary antioxidants is mainly significant in GC-diagnosed patients under severe stress. Those who smoke, have gastric reflux, or are exposed to air pollution. According to Terry et al., intakes of the antioxidants in different types of cancers are not different, except for esophagus cancer [35]. Thus, GC etiology is diverse, and a comprehensive diet assessment can be an effective strategy for understanding its roles.

In addition, the researchers $[36,37]$ concluded an association between MDA and GC. They observed that medication could be used as a predictor of GC $[36,37]$. In addition, this study showed that DAI as a continuous variable is associated with GC's odds. These results confirm other studies [36, 37]. Therefore, the association observed in this study between DAI, TAC, and GC 
Table 5 Odds ratios and confidence intervals for the association between dietary antioxidant index (DIA) and gastric cancer $(n=177)$

\begin{tabular}{|c|c|c|c|c|c|}
\hline \multirow[t]{2}{*}{ DAI } & \multicolumn{2}{|c|}{ DAI (categorical) ${ }^{c} \mathrm{OR}$ and $95 \% \mathrm{Cl}$} & \multirow[t]{2}{*}{$p$ value $^{a}$} & \multirow{2}{*}{$\begin{array}{l}\text { DAI (continuous) } \\
\text { OR and } 95 \% \mathrm{Cl}\end{array}$} & \multirow[t]{2}{*}{$p$ value } \\
\hline & $-0.19 \leq$ & $-0.19>$ & & & \\
\hline & 1 (ref.) & $0.68(0.37-1.24)$ & $0.20^{\mathrm{a}}$ & $0.65(0.45-0.93)$ & $0.02^{\mathrm{a}}$ \\
\hline & 1 (ref.) & $0.72(0.36-1.42)$ & $0.34^{\mathrm{b}}$ & $0.64(0.43-0.95)$ & $0.02^{b}$ \\
\hline \multirow[t]{4}{*}{ DAQS } & $\begin{array}{c}\text { DAQS (cate } \\
95 \% \mathrm{Cl}\end{array}$ & & & & \\
\hline & $\mathrm{DAQS} \leq 3$ & $\mathrm{DAQS}>3$ & & & \\
\hline & 1 (ref.) & $1.32(0.69-2.53)$ & $0.39^{\mathrm{a}}$ & & \\
\hline & 1 (ref.) & $1.30(0.61-2.73)$ & $0.48^{\mathrm{b}}$ & & \\
\hline
\end{tabular}

\footnotetext{
age-adjusted

b Additionally adjusted for gender, body mass index, smoking, education, H. pylori infection, alcohol consumption, aspirin/NSAIDs use, physical activity, cancer history in the first-degree family, total energy intake

c Median
}

indicates the importance of considering these variables' impact on nutritional assessments. So, they can even be used as predictive biomarkers of GC. Thus, this study and the previous research confirmed a strong association between the serum antioxidant status of the body and the odds of GC. Therefore, the development and validation of a suitable and non-invasive index correlated with serum antioxidants can be an option for dietary antioxidants assessment. In addition, according to the formula of DAI and considering the total energy intake of the individual, this index provides a comprehensive and universal view on the antioxidant status.

\section{Strengths and limitations}

Using a valid FFQ is one of the strengths of this study, which provided the research by registering a complete survey of the participants' dietary intakes. Though recall bias can be a limitation of the FFQ, the proved validity and reliability of the scale, along with a trained expert administration of the survey, increase the results' confidence.

One of our study's significant strengths was to measure the serum TAC and MDA, which allowed us to investigate their association with GC and test their correlation with the designed index. This was important in interpreting the results.

However, the results of this study should be interpreted in light of some limitations. Like other case-control studies, recall bias and select bias (selecting a control group) were important challenges. However, due to the hospital-based case-control study and the use of a valid questionnaire control group's selection and the control group's selection from healthy people, these biases were minimized.
The small sample size could affect the generalization and interpretation of the results. Still, considering the study's outcome, GC, this association appears to be the same in the higher sample size studies; future studies with bigger sample sizes are recommended.

\section{Conclusion}

The study showed that DAI is a valid indicator of dietary antioxidant assessments. It can be used as a predictor of antioxidant status due to its correlation with serum antioxidants levels. Furthermore, the results showed that dietary antioxidants have a significant relationship with $\mathrm{GC}$, which indicates the importance of antioxidants in preventing this cancer. Therefore, the use of dietary antioxidants such as vitamins A, C, E, and minerals such as zinc, manganese, and selenium can be an effective strategy to prevent GC.

\section{Abbreviations}

DAl: Dietary Antioxidant Index; GC: Gastric cancer; TNF-a: Tumor necrosis factor-a; L: Interleukin; TAC: Total antioxidant capacity; MDA: Malondialdehyde; FRAP: Ferric-reducing antioxidant power; TBA: Thiobarbituric acid assay; FFQ: Food Frequency Questionnaire; DAQS: Dietary Antioxidant Quality Score; RDI: Recommended Daily Intake; NSAID: Nonsteroidal anti-inflammatory drug; BMI: Body Mass Index; Cl: Confidence intervals; OR: Odds ratios.

\section{Acknowledgements \\ We would like to thank Dr. Diyako Rahmani for the technical editing of the article.}

\section{Authors' contributions}

FV was responsible for designing the study protocol, writing the paper; DR and FV were responsible for conducting the study; FV, DR, and SHD were responsible for analyzing data and interpreting results. All authors read and approved the final manuscript.

\section{Funding}

This research received no specific grant from any funding agency in the public, commercial, or not-for-profit sectors. 


\section{Availability of data and materials}

Data will not be shared.

\section{Ethics approval and consent to participate}

The local Ethics Review Committee approved the study protocol at Shahid Beheshti University of Medical Sciences, Tehran, Iran.

\section{Consent for publication}

Not applicable.

\section{Competing interests}

The authors declare that there is no conflict of interest regarding the publication of this article.

\section{Author details}

${ }^{1}$ Department of Nutritional Sciences, Arak University of Medical Science, Arāk, Iran. ${ }^{2}$ Department of Nutritional Sciences, Faculty of Nutrition Sciences and Food Technology, National Nutrition and Food Technology Research Institute, Shahid Beheshti University of Medical Sciences, Tehran, Iran. ${ }^{3}$ Cancer Research Center, Shahid Beheshti University of Medical Sciences, Tehran, Iran.

Received: 18 April 2020 Accepted: 24 November 2020

Published online: 01 December 2020

\section{References}

1. Dicken BJ, Bigam DL, Cass C, Mackey JR, Joy AA, Hamilton SM. Gastric adenocarcinoma: review and considerations for future directions. Ann Surg. 2005;241:27-39.

2. Bray F, Ferlay J, Soerjomataram I, Siegel RL, Torre LA, Jemal A. Global cancer statistics 2018: GLOBOCAN estimates of incidence and mortality worldwide for 36 cancers in 185 countries. CA Cancer J Clin. 2018;68:394-424

3. Saika K, Sobue T. Cancer statistics in the world. Gan To Kagaku Ryoho. 2013:40:2475-80.

4. Sitarz R, Skierucha M, Mielko J, Offerhaus GJA, Maciejewski R, Polkowski WP. Gastric cancer: epidemiology, prevention, classification, and treatment. Cancer Manag Res. 2018;10:239-48.

5. Rebbeck TR, Burns-White K, Chan AT, Emmons K, Freedman M, Hunter DJ, Kraft P, Laden F, Mucci L, Parmigiani G, et al. Precision prevention and early detection of cancer: fundamental principles. Cancer Discov. 2018. https://doi.org/10.1158/2159-8290.cd-17-1415.

6. Chen Y, Dutson E, Eibl G. Strategies to prevent obesity-related cancer. JAMA. 2018;319:2442-2442.

7. Vahid F, Shivappa N, Hekmatdoost A, Hebert JR, Poustchi H, Shamsipour A, Eslamparast T, Meibodi M, Rahmani D. Association of Pro-inflammatory dietary intake and non-alcoholic fatty liver disease: findings from Iranian case-control study. Int J Vitam Nutr Res. 2018;88:144-50.

8. Vahid F, Shivappa N, Faghfoori Z, Khodabakhshi A, Zayeri F, Hebert JR, Davoodi SH. Validation of a Dietary Inflammatory Index (DII) and association with risk of gastric cancer: a case-control study. Asian Pac J Cancer Prev. 2018;19:1471-7.

9. Serafini M, Bellocco R, Wolk A, Ekström AM. Total antioxidant potential of fruit and vegetables and risk of gastric cancer. Gastroenterology. 2002;123:985-91.

10. Mocellin MC, Fernandes R, Chagas TR, Trindade EBSM. A meta-analysis of $\mathrm{n}-3$ polyunsaturated fatty acids effects on circulating acute-phase protein and cytokines in gastric cancer. Clin Nutr. 2018;37:840-50.

11. Jeddi F, Soozangar N, Sadeghi MR, Somi MH, Shirmohamadi M, Eftekhar-Sadat A-T, Samadi N. Nrf2 overexpression is associated with P-glycoprotein upregulation in gastric cancer. Biomed Pharmacother. 2018;97:286-92.

12. Khurana RK, Jain A, Jain A, Sharma T, Singh B, Kesharwani P. Administration of antioxidants in cancer: debate of the decade. Drug Discovery Today. 2018;23:763-70.

13. Pham-Huy LA, He H, Pham-Huy C. Free radicals, antioxidants in disease and health. Int J Biomed Sci. 2008:4:89-96.

14. Pandey KB, Rizvi SI. Plant polyphenols as dietary antioxidants in human health and disease. Oxid Med Cell Longev. 2009:2:270-8.
15. Lobo V Patil A, Phatak A, Chandra N. Free radicals, antioxidants and functional foods: Impact on human health. Pharmacogn Rev. 2010;4:118-26.

16. Fang Y-Z, Yang S, Wu G. Free radicals, antioxidants, and nutrition. Nutrition. 2002;18:872-9.

17. Abuajah $\mathrm{Cl}$, Ogbonna AC, Osuji CM. Functional components and medicinal properties of food: a review. J Food Sci Technol. 2015;52:2522-9.

18. Kris-Etherton PM, Hecker KD, Bonanome A, Coval SM, Binkoski AE, Hilpert KF, Griel AE, Etherton TD. Bioactive compounds in foods: their role in the prevention of cardiovascular disease and cancer. Am J Med. 2002;113:71-88.

19. Vivekananthan DP, Penn MS, Sapp SK, Hsu A, Topol EJ. Use of antioxidant vitamins for the prevention of cardiovascular disease: meta-analysis of randomised trials. Lancet. 2003;361:2017-23.

20. Hatami M, Vahid F, Akbari ME, Sadeghi M, Ameri F, Eini-Zeinab H, Jamshidi-Naeini Y, Davoodi SH. The vitamins involved in one-carbon metabolisms are associated with reduced risk of breast cancer in overall and subtypes. Int J Vitam Nutr Res. 2020;90:131-40.

21. Muhammad N, Steele R, Isbell TS, Philips N, Ray RB. Bitter melon extract inhibits breast cancer growth in preclinical model by inducing autophagic cell death. Oncotarget. 2017:8:66226-36.

22. Bhattacharya S, Muhammad N, Steele R, Kornbluth J, Ray RB. Bitter melon enhances natural killer-mediated toxicity against head and neck cancer cells. Cancer Prev Res (Philadelphia, Pa). 2017;10:337-44.

23. Bhattacharya S, Muhammad N, Steele R, Peng G, Ray RB. Immunomodulatory role of bitter melon extract in inhibition of head and neck squamous cell carcinoma growth. Oncotarget. 2016;7:33202-9.

24. Narita S, Saito E, Sawada N, Shimazu T, Yamaji T, Iwasaki M, Ishihara J, Takachi R, Shibuya K, Inoue M, Tsugane S. Dietary consumption of antioxidant vitamins and subsequent lung cancer risk: The Japan Public Health Center-based prospective study. Int J Cancer. 2018;142:2441-60.

25. Chatterjee A, Ronghe A, Padhye SB, Spade DA, Bhat NK, Bhat HK. Antioxidant activities of novel resveratrol analogs in breast cancer. J Biochem Mol Toxicol. 2018;32:e21925.

26. Valentovic MA. Chapter Six-Evaluation of resveratrol in cancer patients and experimental models. In: Tew KD, Fisher PB, editors. Advances in cancer research, vol. 137. Cambridge: Academic Press; 2018. p. 171-88.

27. Wright ME, Mayne ST, Stolzenberg-Solomon RZ, Li Z, Pietinen P, Taylor PR, Virtamo J, Albanes D. Development of a comprehensive dietary antioxidant index and application to lung cancer risk in a cohort of male smokers. Am J Epidemiol. 2004:160:68-76.

28. Luu HN, Wen W, Li H, Dai Q, Yang G, Cai Q, Xiang YB, Gao YT, Zheng W, Shu $\mathrm{XO}$. Are dietary antioxidant intake indices correlated to oxidative stress and inflammatory marker levels? Antioxid Redox Signal. 2015;22:951-9.

29. Kolarzyk E, Pietrzycka A, Zajac J, Morawiecka-Baranek J. Relationship between dietary antioxidant index (DAl) and antioxidants level in plasma of Krakow inhabitants. Adv Clin Exp Med. 2017;26:393-9.

30. Ekström AM, Serafini M, Nyrén O, Hansson L-E, Ye W, Wolk A. Dietary antioxidant intake and the risk of cardia cancer and noncardia cancer of the intestinal and diffuse types: a population-based case-control study in Sweden. Int J Cancer. 2000;87:133-40

31. González CA, Pera G, Agudo A, Bueno-de-Mesquita HB, Ceroti M, Boeing H, Schulz M, Del Giudice G, Plebani M, Carneiro F, et al. Fruit and vegetable intake and the risk of stomach and oesophagus adenocarcinoma in the European Prospective Investigation into Cancer and Nutrition (EPICEURGAST). Int J Cancer. 2006:118:2559-66.

32. Serafini M, Jakszyn P, Lujan-Barroso L, Agudo A, Bas Bueno-de-Mesquita $H$, van Duijnhoven FJ, Jenab M, Navarro C, Palli D, Boeing H, et al. Dietary total antioxidant capacity and gastric cancer risk in the European prospective investigation into cancer and nutrition study. Int J Cancer. 2012:131:E544-554.

33. Rivas A, Romero A, Mariscal-Arcas M, Monteagudo C, Lopez G, Lorenzo ML, Ocana-Peinado FM, Olea-Serrano F. Association between dietary antioxidant quality score (DAQs) and bone mineral density in Spanish women. Nutr Hosp. 2012;27:1886-93.

34. Wang Y, Yang M, Lee SG, Davis CG, Koo SI, Chun OK. Dietary total antioxidant capacity is associated with diet and plasma antioxidant status in healthy young adults. J Acad Nutr Diet. 2012;112:1626-35.

35. Terry P, Lagergren J, Ye W, Nyrén O, Wolk A. Antioxidants and cancers of the esophagus and gastric cardia. Int J Cancer. 2000;87:750-4.

36. Baliga S, Chaudhary M, Bhat S, Bhansali P, Agrawal A, Gundawar S. Estimation of malondialdehyde levels in serum and saliva of children 
affected with sickle cell anemia. J Indian Soc Pedodontics Prev Dentistry. 2018;36:43-7.

37. Wang YK, Chiang WC, Kuo FC, Wu MC, Shih HY, Wang SSW, Liu CJ, Chen YH, Wu DC, Su WW, Huang YL. Levels of malondialdehyde in the gastric juice: its association with Helicobacter pylori infection and stomach diseases. Helicobacter. 2018;23:e12460.

38. Vahid F, Rahmani G, Jafari Naeini A, Falahnejad H, Davoodi SH. The Association Between Index of Nutritional Quality (INQ) and gastric cancer and evaluation of nutrient intakes of gastric cancer patients: a case-control study. Int J Cancer Manag. 2018;11(1):e9747.

\section{Publisher's Note}

Springer Nature remains neutral with regard to jurisdictional claims in published maps and institutional affiliations.
Ready to submit your research? Choose BMC and benefit from:

- fast, convenient online submission

- thorough peer review by experienced researchers in your field

- rapid publication on acceptance

- support for research data, including large and complex data types

- gold Open Access which fosters wider collaboration and increased citations

- maximum visibility for your research: over $100 \mathrm{M}$ website views per year

At BMC, research is always in progress.

Learn more biomedcentral.com/submissions 